\title{
Sex differences in the toxicity of polyethylene glycol-coated gold nanoparticles in mice
}

This article was published in the following Dove Press journal:

International Journal of Nanomedicine

3 July 2013

Number of times this article has been viewed

Jie Chen
Hao Wang
Wei Long
Xiu Shen
Di Wu
Sha-Sha Song
Yuan-Ming Sun
Pei-Xun Liu
Saijun Fan
Feiyue Fan
Xiao-Dong Zhang

Tianjin Key Laboratory of Molecular Nuclear Medicine, Institute of Radiation Medicine, Chinese Academy of Medical Sciences and Peking Union Medical College, Tianjin, People's Republic of China
Correspondence: Xiao-Dong Zhang Tianjin Key Laboratory of Molecular Nuclear Medicine, Institute of Radiation Medicine, Chinese Academy of Medical Sciences and Peking Union Medical College, No 238, Baidi Road,

Nankai District, Tianjin,

People's Republic of China

Tel 862285683046

Fax 862285683046

Email xiaodongzhang@tju.edu.cn

\begin{abstract}
Gold nanoparticles have received wide interest in disease diagnosis and therapy, but one of the important issues is their toxicological effects in vivo. Sex differences in the toxicity of gold nanoparticles are not clear. In this work, body weight, organ weight, hematology, and biochemistry were used to evaluate sex differences in immune response and liver and kidney damage. Pathology was used to observe the general toxicity of reproductive organs. The immune response was influenced significantly in female mice, with obvious changes in spleen and thymus index. Hematology results showed that male mice treated with $22.5 \mathrm{~nm}$ gold nanoparticles received more significant infection and inflammation than female mice. Meanwhile, the biochemistry results showed that 4.4 and $22.5 \mathrm{~nm}$ gold nanoparticles caused more significant liver damage in male mice than female mice, while 22.5, 29.3, and $36.1 \mathrm{~nm}$ gold nanoparticles caused more significant kidney damage in female mice than male mice. No significant toxicological response was found in the reproductive system for female or male mice. It was found that gold nanoparticles caused more serious liver toxicity and infection in male mice than female mice. These findings indicated that sex differences may be one of the important elements for in vivo toxicity of gold nanoparticles.
\end{abstract}

Keywords: sex differences, toxicity, gold nanoparticles

\section{Introduction}

More and more attention has been focused on gold-based nanomaterials in diverse biomedical applications, such as biosensors, ${ }^{1}$ optical imaging, ${ }^{2,3}$ photothermal therapy, ${ }^{4,5}$ and drug delivery, ${ }^{6}$ due to their unique surface chemistry and tunable optical properties. ${ }^{7-13}$ Recently, gold nanoparticles (NPs) have also been conceived as contrast agents of X-ray imaging for cancer therapy, because of their enhancement effects in photoelectronic absorption and secondary electron generation. ${ }^{14-17}$ Compared with other novel therapy methods, radiation therapy is closely related to clinical application which means that it is necessary to accept more rigorous topological examination and toxicological observation for gold nanostructures. ${ }^{18}$ Thus, it is of interest to investigate the topological response in detail, which will benefit both nanopharmacology and nanotoxicology.

In vivo biocompatibilities of gold NPs have been widely investigated in recent years. ${ }^{19-21}$ It has been demonstrated that the toxicity of gold-based nanomaterials is closely related to surface chemistry, ${ }^{22-24}$ physical dimension, ${ }^{25-30}$ dose, ${ }^{31}$ and administration routes. ${ }^{31}$ In particular, surface chemistry plays an important role in the toxicity of gold NPs. Naked gold NPs are not stable in the physiological environment, and can form $100 \mathrm{~nm}$ aggregators in blood by interaction between NPs and proteins. ${ }^{16,32}$ These hybrid 
aggregators can be absorbed rapidly by the reticuloendothelial system, and arrive at the liver and spleen. ${ }^{33,34}$ Polyethylene glycol (PEG) coating can reduce the surface charge (zeta potential), and thus improve blood stability. ${ }^{34}$ Compared with naked gold NPs, PEG-coated gold NPs can present relatively monodisperse distribution in the physiological environment. Meanwhile, PEG-modified NPs present long-term blood circulation and long blood half-life. It was found that PEGcoated gold NPs and nanorods at $10 \mathrm{mg} / \mathrm{kg}$ could increase the duration of blood circulation and tumor distribution. ${ }^{35}$ In spite of these benefits, the toxicity response of PEG-coated gold NPs in tail-vein injection $10-100 \mathrm{mg} / \mathrm{kg}$ still caused liver and kidney injuries and abnormal gene expression in liver and spleen owing to particle accumulation. ${ }^{36}$ Thus, it is generally accepted that long-term accumulation of gold NPs will inevitably produce side effects in vivo. Besides, size is another important element for in vivo toxicity of NPs. For instance, 5 and $30 \mathrm{~nm}$ particles could lead to an increase of biochemical indicators, but 10 and $60 \mathrm{~nm}$ particles caused relatively slight damage in the liver. ${ }^{16,27,29,30,37}$ Additionally, typical $13.5 \mathrm{~nm}$ PEG-coated NPs preferred to accumulate in the liver and spleen, but NPs larger than $100 \mathrm{~nm}$ could be cleared partially by excretion. ${ }^{29}$

Apart from these elements, sex is an easily overlooked factor that also attracts our interest. Indeed, it has been demonstrated that sex differences are an important aspect in pharmacokinetic and pharmacodynamics research. ${ }^{38} \mathrm{An}$ obvious significant sex difference is physiological change during the menstrual cycle, as well as changes in plasma protein and hormonal levels. ${ }^{39}$ These elements can cause possible effects on interactions between blood plasma and NPs, and thus induce different physiological responses during blood circulation for males and females. Therefore, sex differences result in possible toxicological differences, eg, reproductive system and liver injury. In the field of nanotoxicology, it has been demonstrated that sex differences can lead to significant differences in the toxicity of Ag NPs. It was found that exposure to more than $300 \mathrm{mg}$ of $60 \mathrm{~nm} \mathrm{Ag}$ NPs in Sprague Dawley rats may lead to liver damage. ${ }^{40,41}$ Meanwhile, it has been found that Ag NPs at a low dose $(<10 \mathrm{mg} / \mathrm{kg})$ were safe for biomedical application and had no side effects, but high dosages $(>20 \mathrm{mg} / \mathrm{kg})$ were toxic. These results inspired us to investigate sex difference-related toxicity.

In our previous work, we investigated size-dependent, administration route-dependent toxicity of gold NPs. Especially, it was found that glutathione-protected $\mathrm{Au}$ nanoclusters are low toxic and metabolizable. ${ }^{16,17,24,29,31}$ In the present study, we investigated sex differences in in vivo toxicity of four kinds of gold NPs. The widely used PEG coating was employed for the NPs. In the experiment, we observed sex differences in immune responses and liver and kidney injuries, based on the evaluation of body weights, organ indexes, hematology, and biochemistry. Histopathology changes were investigated to show the general toxicity of reproductive organs.

\section{Materials and methods}

\section{Fabrication}

The gold NPs were synthesized following the classical method devised by Turkevich et al. ${ }^{42}$ Chloroauric acid $\left(\mathrm{HAuCl}_{4} 4 \mathrm{H}_{2} \mathrm{O}\right)$ solution $(10 \mathrm{~mL}, 0.1 \%)$ was brought to a boil, then $1.3,0.8$, and $0.5 \mathrm{~mL}$ of $1 \%$ preheated sodium citrate solution were added respectively to the boiling solution. The reduction reaction was completed after 5 minutes, and the solution was then boiled for a further 30 minutes and left at room temperature. The spherical gold NPs of about 22.5, 29.3 , and $36.1 \mathrm{~nm}$ size could be synthesized by this method. However, gold NPs of $4.4 \mathrm{~nm}$ size should be obtained by $\mathrm{NaBH}_{4}$. Subsequently, $\mathrm{PEG}_{2000}$-sulfhydryl (SH) (1 mg; Yare Biotech, Shanghai, People's Republic of China) was added to the NP solutions and stirred for 1 hour to synthesize the PEG-coated gold NPs. Subsequently, excess $\mathrm{PEG}_{2000}-\mathrm{SH}$ molecules could be removed by ultrafiltration using $10 \mathrm{kDa}$ molecular weight cutoff filters and washed several times with pure water.

\section{Physical properties of materials}

Optical absorption spectra in the wavelength range of 200-850 nm were measured with a DU800 Spectrophotometer (Beckman Coulter, Brea, CA, USA) in a $5 \mathrm{~mL}$ glass cuvette with $2.5 \mathrm{~nm}$ slit width. The zeta $(\zeta)$ potential of the gold NPs was determined with the Nano ZS Zetasizer particle analyzer (Malvern Instruments, Malvern, UK). Data were acquired in the phase-analysis light-scattering mode at $25^{\circ} \mathrm{C}$, and sample solutions were prepared by diluting gold NPs into $10 \mathrm{mM}$ phosphate-buffered saline solution ( $\mathrm{pH}$ 7.4). For the transmission electron microscope (TEM) analysis, NPs were observed using a Hitachi (Tokyo, Japan) HF-2000 fieldemission high-resolution TEM operating at $200 \mathrm{kV}$.

\section{Animal administration}

Animals were purchased, maintained, and handled with protocols approved by the Institute of Radiation Medicine, Chinese Academy of Medical Sciences. The C57 mice (30 female and male) were obtained from the institute's laboratories 
at 11 weeks of age and were housed in a 12-hour/12-hour light/dark cycle, and were given food and water ad libitum. Thirty female (or 30 male) mice were randomly divided into five groups (six in each group): control group, and four experimental groups for treatment with differently sized PEG-coated gold NPs. The mice received an intraperitoneal injection of approximately $200 \mu \mathrm{L}$ of gold NP solution at a dose of $4000 \mu \mathrm{g} / \mathrm{kg}$, based on the previously identified toxic dose in vivo. ${ }^{16,29}$ The mice were weighed and assessed for behavior after injection every 2 days for 28 days.

\section{Hematology, biochemistry, and sample collection}

After 28 days of treatment, all mice were killed, and blood was collected for blood chemistry, biochemistry, and organ studies. Using a standard blood-collection technique, we drew $200 \mu \mathrm{L}$ blood from the saphenous vein into a potassium ethylenediaminetetraacetic acid-collection tube for hematology analysis. Mice were killed using isoflurane anesthetic and angiocatheter exsanguination with phosphatebuffered saline. During necropsy, liver, kidneys, spleen, heart, lung, thymus, uterus, ovaries, and testis were collected and weighed. One female and male mouse from each group was fixed with $10 \%$ buffered formalin following phosphatebuffered saline exsanguination. To examine the immune response explicitly, spleen and thymus indexes $\left(\mathrm{S}_{x}\right)$ can be defined as:

$$
\mathrm{S}_{x}=\frac{\text { Weight of experimental organ }(\mathrm{mg})}{\text { Weight of experimental animal }(\mathrm{g})}
$$
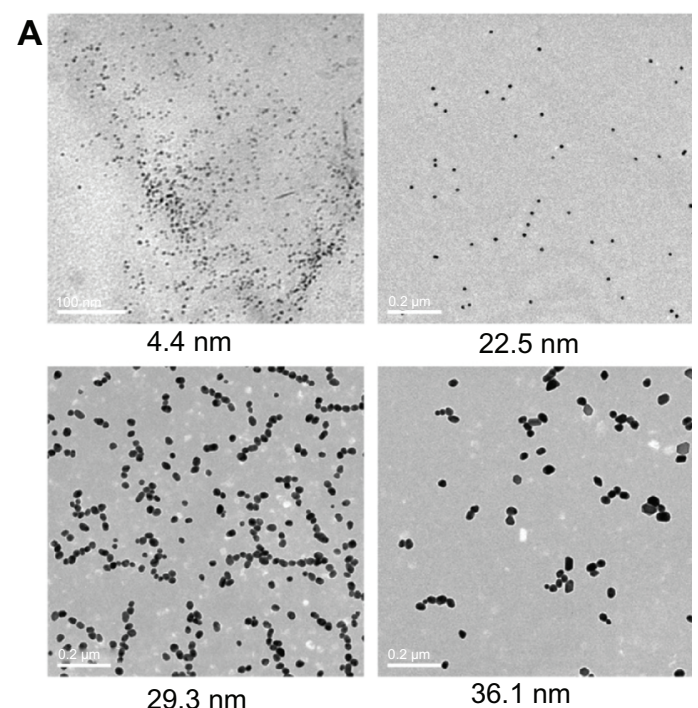

B

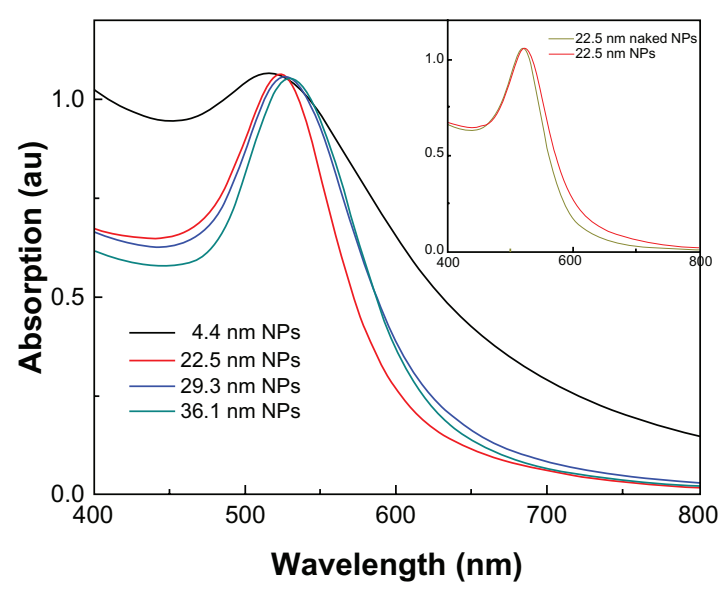

Major organs from those mice were processed routinely into paraffin, and stained with hematoxylin and eosin. Pathology was examined using a digital microscope.

\section{Results and discussion TEM and spectrophotometer}

The TEM images and optical absorption of gold NPs can be seen in Figure 1. The average sizes of gold NPs were about 4.4, 22.5, 29.3, and $36.1 \mathrm{~nm}$ (Figure 1A), which is close to that of previous work. ${ }^{29}$ Significant optical absorption peaks, namely surface plasmon resonance (SPR), can be seen for all NPs in Figure 1B. The absorption center is located at 516, 522, 527, and $529 \mathrm{~nm}$, corresponding to 4.4, 22.5, 29.3, and $36.1 \mathrm{~nm}$ gold NPs, respectively. The strong absorption peaks can be interpreted by the interaction between excitation light and metal NPs. The SPR can be reformulated by Mie's classic theory. ${ }^{43}$ With increase in particle size, the SPR will shift to long-wavelength regions, which is consistent with the reported results. ${ }^{44}$ The $\mathrm{PEG}_{2000}$ coating is not macromolecules, thus it is not expected that the SPR will shift obviously. Actually, we found that $\mathrm{PEG}_{2000}$ only made a very tiny contribution to SPR shift. For example, the SPR of $22.5 \mathrm{~nm}$ naked gold NPs is at $519 \mathrm{~nm}$, while the SPR of $22.5 \mathrm{~nm}$ PEG-coated gold NPs is located at $522 \mathrm{~nm}$, which can be seen in Figure 1B. Besides, the surface chemical activity can be modified by adding the PEG coating. The $\zeta$-potentials of $4.4,22.5,29.3$, and $36.1 \mathrm{~nm}$ naked gold particles were $-28.1,-16.23,-8.7$, and $-8.27 \mathrm{mV}$, respectively, due to citric acid coating and negative charge on the surface. The PEG-SH coating induced decreases of $\zeta$-potentials

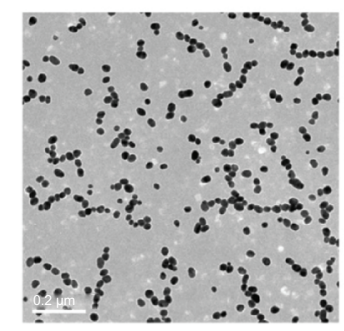

$29.3 \mathrm{~nm}$

$36.1 \mathrm{~nm}$

Figure I (A) Transmission electron microscopy images of 4.4, 22.5, 29.3, and 36.I nm nanoparticles (NPs). (B) Optical absorption of the polyethylene glycol-coated gold NPs. 
to $-6.01,-1.92,-1.89$, and $-0.98 \mathrm{mV}$, respectively. So the PEG-SH coating can decrease $\zeta$-potentials and improve the monodispersity of gold NPs.

\section{Body weight and organ weights}

Figure 2 shows the variation in body weight of mice treated with gold NPs of different sizes. Figure 2A and B present the body weights of female and male mice over 28 days, respectively. The body weight of the mice was measured every 2 days. Each point represents the mean \pm standard deviation of six mice. Data were analyzed using analysis of variance with SPSS 13.0 (IBM, Armonk, NY, USA), and the differences between the different groups and control group for each organ were not significant $(P>0.05)$. Average body weight of control female mice was $29 \mathrm{~g}$, while body weights of 4.4, 22.5, 29.3, and $36.1 \mathrm{~nm}$ NP-treated mice were about $31,31,32$, and $30 \mathrm{~g}$, respectively, at 28 days. Similar results can be found in male mice. It can be seen in Figure 2A that the body weight of mice treated with $22.5 \mathrm{~nm}$ gold NPs significantly changed, which also can be found in Figure 2B. Other-size NPs, such as 4.4, 29.3, and $36.1 \mathrm{~nm}$, exhibited very small deviations. Generally, it was found that the standard deviation of male mice was larger than that of female mice. Furthermore, no abnormal clinical signs or behaviors were detected in the control or treated groups. Figure 3 gives the liver, heart, lung, and kidney indexes of mice treated with gold NPs of different sizes. It can be found that the weights of the heart, liver, spleen, lung, and kidneys showed no obvious variation at a dose of $4000 \mu \mathrm{g} /$ $\mathrm{kg}$. It is necessary to investigate the organ indexes for the spleen and thymus further.

A

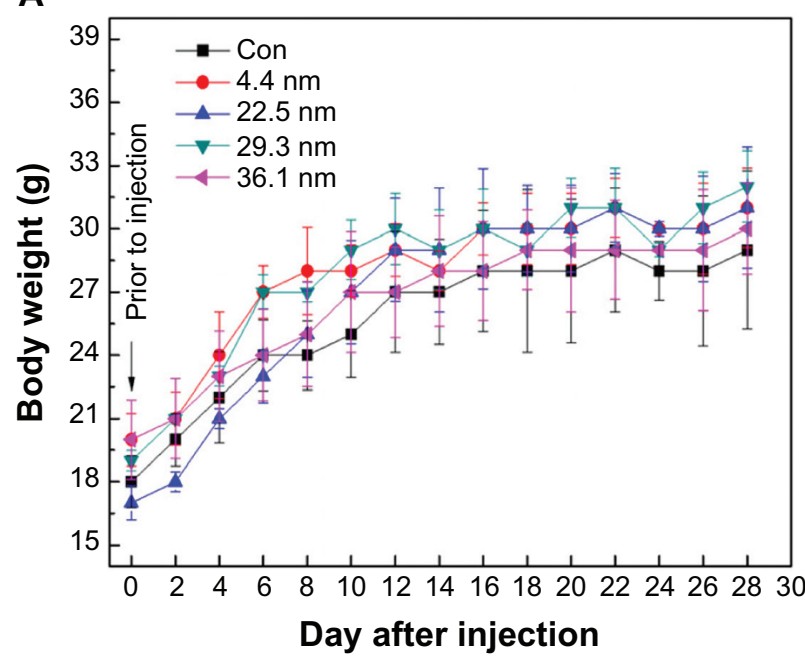

\section{Immune response and pathology}

Figure 4 shows the immune response of mice treated by gold NPs based on spleen and thymus index. We calculate the spleen index and thymus index of female mice (Figure 4A) and male mice (Figure 4B) to examine immune system damage induced by the PEG-coated gold NPs in mice. For the female mice, the average values of thymus and spleen index in the control group were 2.7 and 3.3, respectively. In the NP groups, 4.4, 22.5, and $29.3 \mathrm{~nm}$ NPs did not induce significant changes, but $36.1 \mathrm{~nm}$ gold NP-treated female mice presented a sharp increase in spleen index. Generally speaking, the increase in spleen index indicates the immune response of mice, which has been widely reported elsewhere. ${ }^{45}$ For the treated male mice, the average values of thymus and spleen index in the control group were 1.7 and 5.1, respectively. The spleen index of 4.4, 22.5, 29.3, and $36.1 \mathrm{~nm}$ gold NP-treated male mice changed to $1.5,3.3,3.1$, and 3.8 , respectively. It can be seen that the spleen index of the male mice treated with $4.4 \mathrm{~nm}$ gold NPs decreased. For the treated male mice, the spleen and thymus index showed no significant changes (Figure 4B). As a contrast, for the female mice, the organ indexes of gold NP-treated groups had significant statistical differences when compared with the control group.

The indexes of spleen and thymus are important indicators for the immune system of mice. ${ }^{45}$ Changes in spleen and thymus index always indicate that the organism is assaulted by enthetic invasion, which will cause potential toxicological response. Besides, increases in other organ indexes infer that the organism is being protected, with the toxicity responses released. It is known that PEG-coated NPs prefer to accumulate in the spleen. In spite of no obvious statistical

B

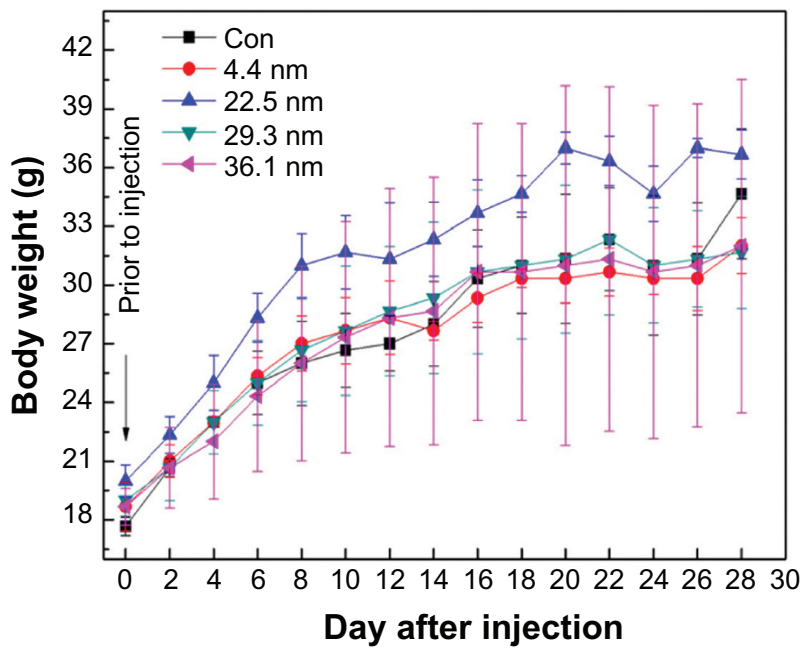

Figure 2 Body-weight changes in female mice (A) and male mice (B) for the 4.4, 22.5, 29.3, and 36.1 nm gold nanoparticles at a dose of $4000 \mu g / k g$. The body weight of the treated mice was measured every 2 days. Each point represents the mean \pm standard deviation of six mice. Data were analyzed using analysis of variance with SPSS I3.0, and the differences between the different groups and control (Con) group for each organ were not significant $(P>0.05)$. 


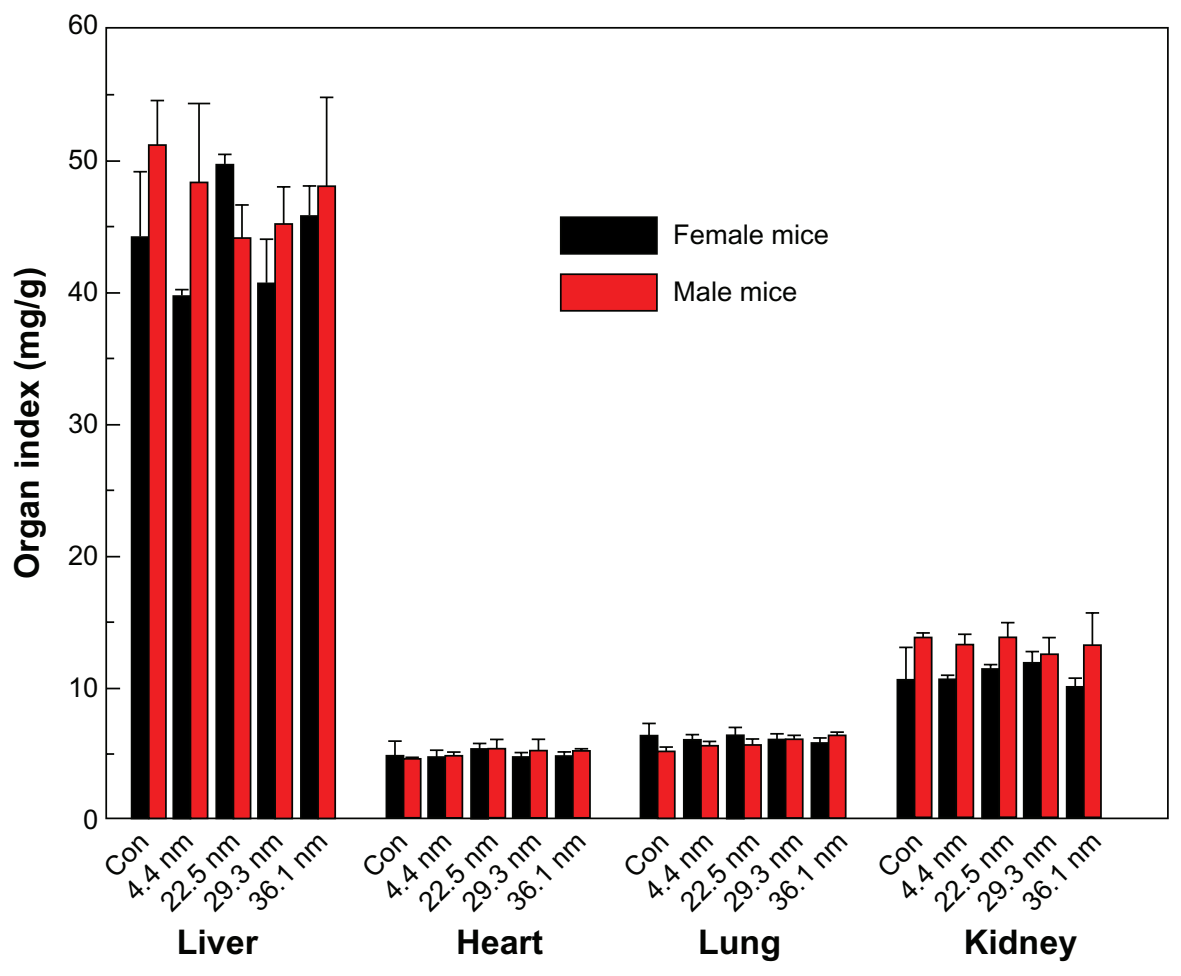

Figure 3 Liver, heart, lung, and kidney indexes of female and male mice. Bars represent mean \pm standard deviation. Data were analyzed using analysis of variance with SPSS 13.0, and the differences between the different groups and control (Con) group for each organ were not significant $(P>0.05)$.

difference, the PEG-coated $36.1 \mathrm{~nm}$ NPs still caused a change in spleen index in female mice. These changes impelled us to explore more findings through hematology and biochemistry.

\section{Hematology and biochemistry}

When NPs are intravenously administered, the first physiological system they interact with in vivo is the blood and blood components. Then they may induce inflammatory responses, which will increase or decrease the activity of the immune system, and alteration of hematology factors, such as white blood cells. Therefore, understanding the properties of hemocompatibility is an important step during the initial characterization process of NPs. Figure 5 shows the hematology analysis of female and male mice treated by differently sized NPs. We selected standard hematology markers for analysis, such as white blood cells (WBCs), red blood cells (RBCs), hematocrit (HCT), mean corpuscular volume (MCV), hemoglobin (HGB), platelets (PLTs), mean corpuscular hemoglobin $(\mathrm{MCH})$, and mean corpuscular hemoglobin concentration (MCHC). For the female mice, two important indicators, the WBC and RBC, did not show significant changes. The HGB of the mice treated with $22.5 \mathrm{~nm}$ gold NPs was as high as $309 \mathrm{~g} / \mathrm{l}$, while that of the control group was just $177 \mathrm{~g} / \mathrm{l}$. Meanwhile, the $\mathrm{MCH}$ and
$\mathrm{MCHC}$ of the mice treated with $22.5 \mathrm{~nm}$ gold NPs also increased significantly. The $\mathrm{MCH}$ sharply increased from 20 to 33, and the MCHC rose from $420 \mathrm{~g} / 1$ to $850 \mathrm{~g} / 1$. Other parameters such as PLT and HCT showed no significant difference. As expected, for the male mice, the results were different from the female mice. The $\mathrm{WBC}$ of the mice treated with 22.5 and $36.1 \mathrm{~nm}$ gold NPs showed significant statistical differences when compared with the control group. WBC increased to $3 \times 109 / \mathrm{L}$ for $22.5 \mathrm{~nm}$ NP-treated mice, and $8.2 \mathrm{~g} / 1$ for $36.1 \mathrm{~nm}$ NP-treated mice. Meanwhile, RBC, PLT, and HCT of the mice treated with $22.5 \mathrm{~nm}$ increased significantly. In particular, RBC significantly increased from $3 \times 1012 /$ L. Other parameters showed no significant differences. It is clearly shown that sex difference is notable for toxicological response.

As is well known, WBC and $\mathrm{RBC}$ are the most important indicators for in vivo response, which are directly related to infection and inflammation. Male mice treated with $22.5 \mathrm{~nm}$ particles showed notable variations in WBC and $\mathrm{RBC}$, which suggests that serious infections may have occurred. Meanwhile, the increase in WBC seen in male mice treated with $36.1 \mathrm{~nm}$ NPs may also have been connected to infections. In contrast, the gold NPs did not induce significant increases of RBC and WBC for female mice, which indicates that gold NPs cause more significant infections for male mice 

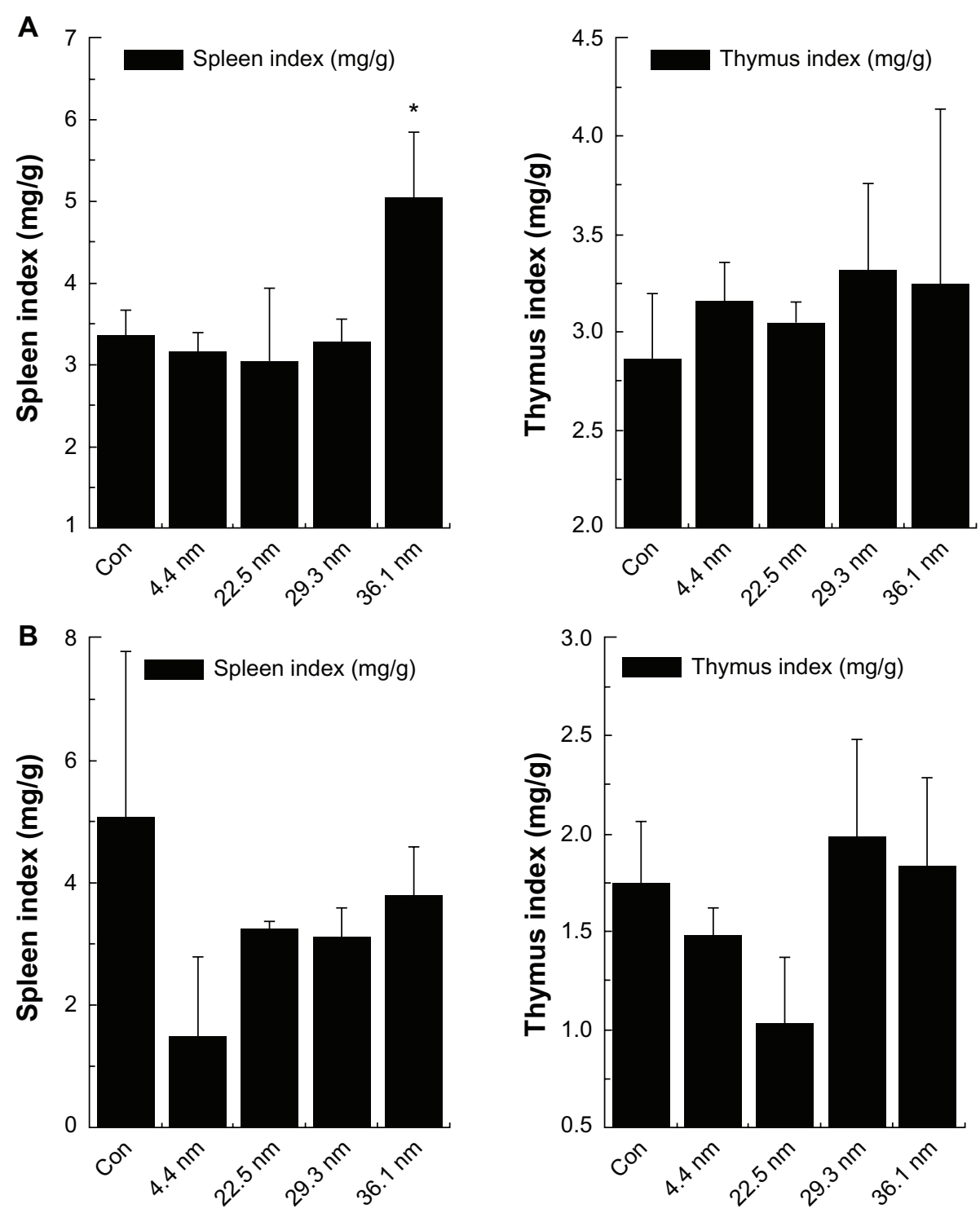

Figure 4 Spleen index and thymus index of female mice $(\mathbf{A})$ and male mice $(\mathbf{B})$. Bars represent mean \pm standard deviation. Data were analyzed using analysis of variance with SPSS 13.0, and the differences between the different groups and control (Con) group for each organ were not significant $(P>0.05)$. $*$ Represent significant differences from the control.

than female mice. The HGB, MCH, and MCHC of $22.5 \mathrm{~nm}$ NP-treated female mice and PLT and HCT of $22.5 \mathrm{~nm}$ NP-treated male mice showed significant differences when compared with the control, but WBC and $\mathrm{RBC}$ reach a stable level. Differently sized NPs can induce significant difference for in vivo toxicity, but generally male mice may suffer more serious toxicity than female mice. Besides, for size-dependent effects, it is clear that $22.5 \mathrm{~nm}$ gold NP-treated mice presented with significant infections, as shown by increased WBC and RBC levels. As a contrast, 4.4 and $29.3 \mathrm{~nm}$ gold NP-treated mice did not show any significant infections.

After the NPs leave the bloodstream, they will arrive at the liver and kidneys. Therefore, it is necessary to clarify/ investigate whether or not the NPs can induce toxicity for these organs. By measuring a variety of biochemical factors in the blood serum, it is possible to assess liver-function failure, hepatocellular injury, and cholestasis. To confirm these results, we investigated the blood biochemistry index. We present the biochemistry results of the NPs in Figure 6, comprising alanine transaminase (ALT), aspartate transaminase (AST), blood urea nitrogen (BUN), creatinine (CREA), total protein (TP), albumin (ALB), globulin (GLOB), and total bilirubin (TBIL). For the female mice, in Figure 6 it is observed that the CREA of the mice treated with 22.5, 29.3, and $36.1 \mathrm{~nm}$ NPs significantly decreased to $8 \mu \mathrm{M}$, $5.8 \mu \mathrm{M}$, and $8 \mu \mathrm{M}$, respectively. Meanwhile, the ALB level of the mice treated with $29.3 \mathrm{~nm}$ NPs increased significantly from $32 \mathrm{~g} / \mathrm{L}$ to $35 \mathrm{~g} / \mathrm{L}$. The TBIL level of mice treated with 


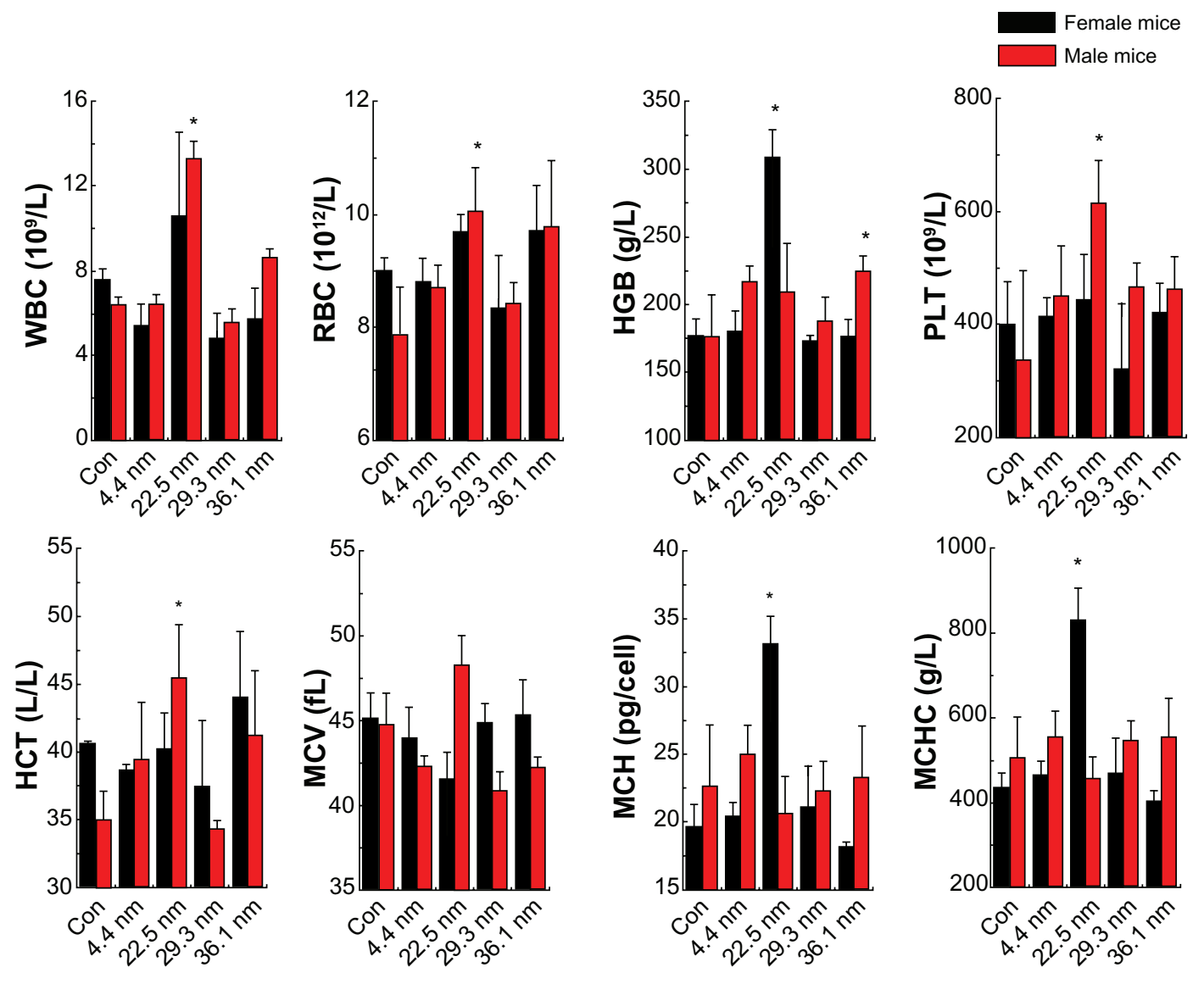

Figure 5 Hematology results of the nanoparticles, including the hematology results of the female and male mice. These results show means and standard deviation of white blood cells (WBC), red blood cells (RBC), hemoglobin (HGB), platelets (PLT), hematocrit (HCT), mean corpuscular volume (MCV), mean corpuscular hemoglobin (MCH), and mean corpuscular hemoglobin concentration (MCHC). Bars represent means \pm standard deviation. Data were analyzed by Student's $t$-test, and stars represent significant differences from the control (Con) group $(P<0.05)$. * Represent significant differences from the control.

4.4 and $36.1 \mathrm{~nm}$ NPs showed significant differences when compared with the control group. For the male mice, the ALT of the mice treated with 4.4, 22.5 and $36.1 \mathrm{~nm}$ NPs increased significantly to $115 \mathrm{U} / \mathrm{L}, 93 \mathrm{U} / \mathrm{L}$, and $105 \mathrm{U} / \mathrm{L}$, respectively. Meanwhile, the AST of the mice treated with $22.5 \mathrm{~nm}$ significantly increased from $130 \mathrm{U} / \mathrm{L}$ to $250 \mathrm{U} / \mathrm{L}$. The CREA of the mice treated with $29.3 \mathrm{~nm}$ NPs also showed significant statistical differences, increasing from $8 \mu \mathrm{M}$ to $12 \mu \mathrm{M}$, while the TP of the $4.4 \mathrm{~nm}$ group and ALB of the $36.1 \mathrm{~nm}$ group both decreased. These results clearly show significant liver and kidney toxicity for all these NPs.

In blood biochemistry, ALT and AST are dominant indicators for liver toxicity. The former is specific for cellular damage in the liver, and the latter is nonspecific. Reduction of liver function and cholestasis can be assessed by the substances produced by liver, including ALB, GLOB, TP, and TBIL. The significant increase of ALT and AST found in mice probably indicates obvious liver toxicity. In our work, the NP-treated female mice did not show any increase of ALT and AST, but NP-treated male mice showed significant increase of ALT and AST, which clearly shows that male mice suffer more serious liver toxicity than female mice. Meanwhile, CREA is a crucial marker for kidney function. In the results, a sharp decrease of CREA can be found in female mice, which indicates their kidneys may have been damaged. It has been shown that large particles prefer to aggregate in the liver, while small particles can be partially metabolized by renal clearance. Thus, NPs accumulation in the kidneys can induce significant kidney damage. Meanwhile, the PEGcoated gold NPs can form $100 \mathrm{~nm}$ hybrid materials, which will gradually accumulate in the liver by blood circulation. ${ }^{16}$ For sex differences in toxicity, this is interesting. Many hormones have similar chemistry elements. Meanwhile, the amino group is a relatively active group and can absorb gold NPs through the surface by $\mathrm{Au}-\mathrm{NH}_{2}$ covalent binding. Thus, it is most probably the fact that hormones from female mice can delay interaction between gold NPs and blood, and that gold NPs can be partially cleared by the kidneys, reducing liver damage. In contrast, change of hormone level for male mice is not significant, thus inducing the formation of larger 


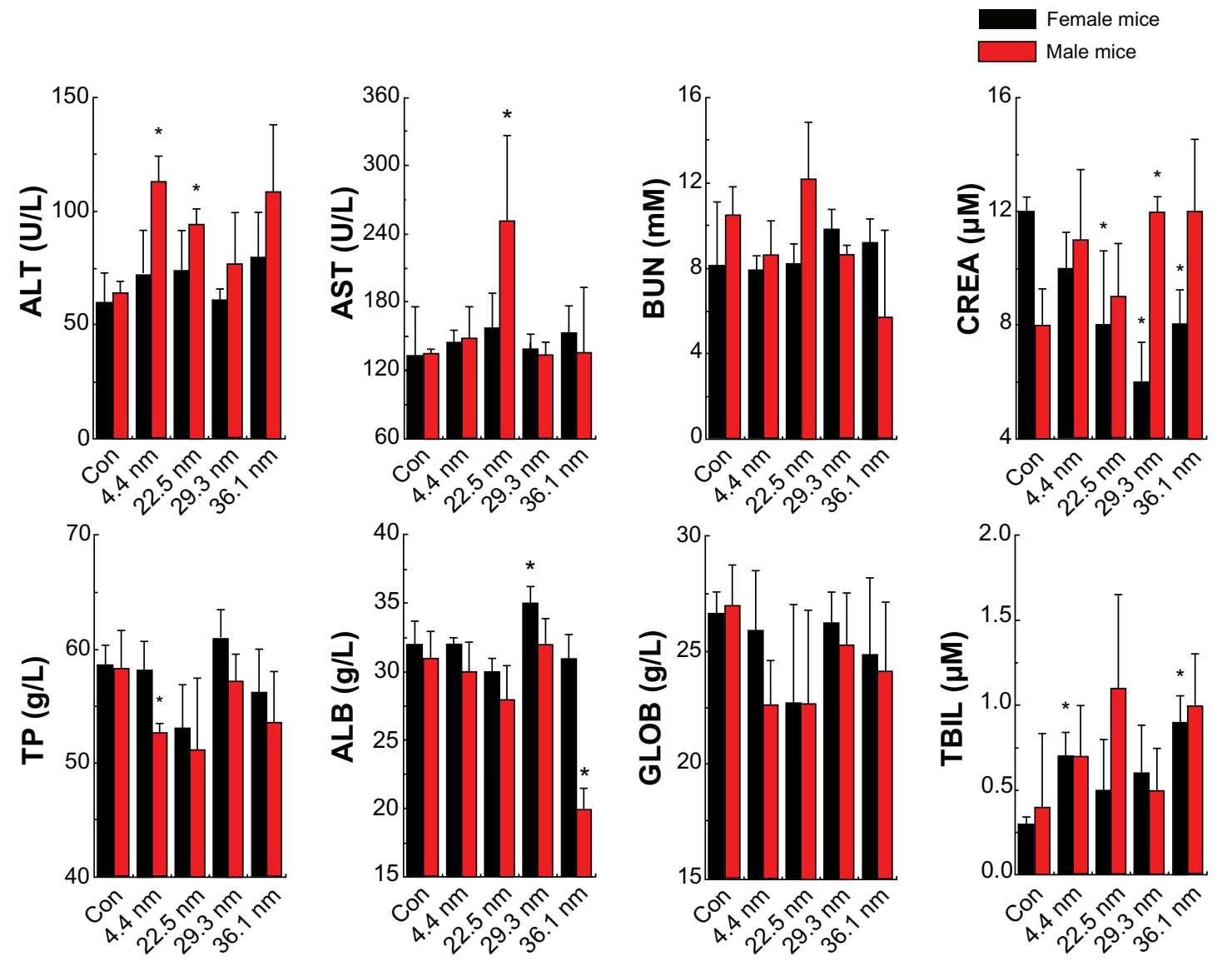

Figure 6 Biochemistry results of the nanoparticles, including the biochemistry results of the female and male mice. These results show means and standard deviations of alanine transaminase (ALT), aspartate transaminase (AST), blood urea nitrogen (BUN), creatinine (CREA), total protein (TP), albumin (ALB), globulin (GLOB), and total bilirubin (TBIL). Bars represent means \pm standard deviation. Data were analyzed by Student's $t$-test, and stars represent significant differences from the control (Con) group $(P<0.05)$. * Represent significant differences from the control.

NPs in the blood and finally accumulating in the liver, causing liver damage. All things considered, male mice will suffer more serious liver toxicity than female mice when treated with gold NPs.

Also, it is important to consider size-dependent effects. It can be seen that $4.4 \mathrm{~nm}$ gold NPs showed minimal liver and kidney toxicity, and no indicators showed any significant variations, except for AST, TBIL, and TP. The $22.5 \mathrm{~nm}$ gold NPs, however, caused significant change of ALT, AST, and CREA, indicating both liver and kidney damage. The 29.3 and $36.1 \mathrm{~nm}$ gold NP-treated mice showed significant kidney and slight liver toxicity. Many investigations ${ }^{27,29,30}$ about size-dependent toxicity have shown that small NPs prefer to accumulate in the kidneys and large NPs in the liver, but the actual behavior of NPs in blood is complex. Our work again confirms that PEG-coated NPs with sizes of 10-30 nm are still not sufficiently safe to use.

Finally, we investigated sex differences in reproductive system toxicity of gold NPs. The reproductive system is also an important indicator for sex differences. To investigate sex differences in toxicity, histological assessment of uterus, ovaries, and testis were performed to determine whether the gold NPs can cause tissue damage. It can be seen from Figure 7 that there were no apparent histopathological abnormalities related to those animals treated with gold NPs. The pathology result provides macroscopic and visual evidence of toxicity. It shows that the PEG-coated gold NPs did not bring about significant reproductive toxicity in mice. Sex differences have not induced the significant difference in reproductive organs.

These results suggest that further metabolism of goldbased materials must be investigated. In vivo toxicity and biodistribution studies show that PEG-coated gold NPs are different from naked gold NPs. We found in previous experiments that $12.1 \mathrm{~nm}$ PEG-coated gold NPs had more efficient diffusion and absorption for tumors, so they were more efficient for targeting tumors. ${ }^{16}$ Nevertheless, naked gold NPs were strongly associated with essential blood 

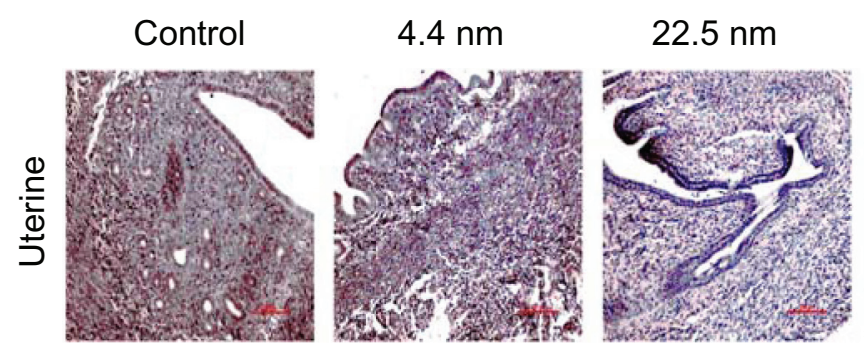

$29.3 \mathrm{~nm}$
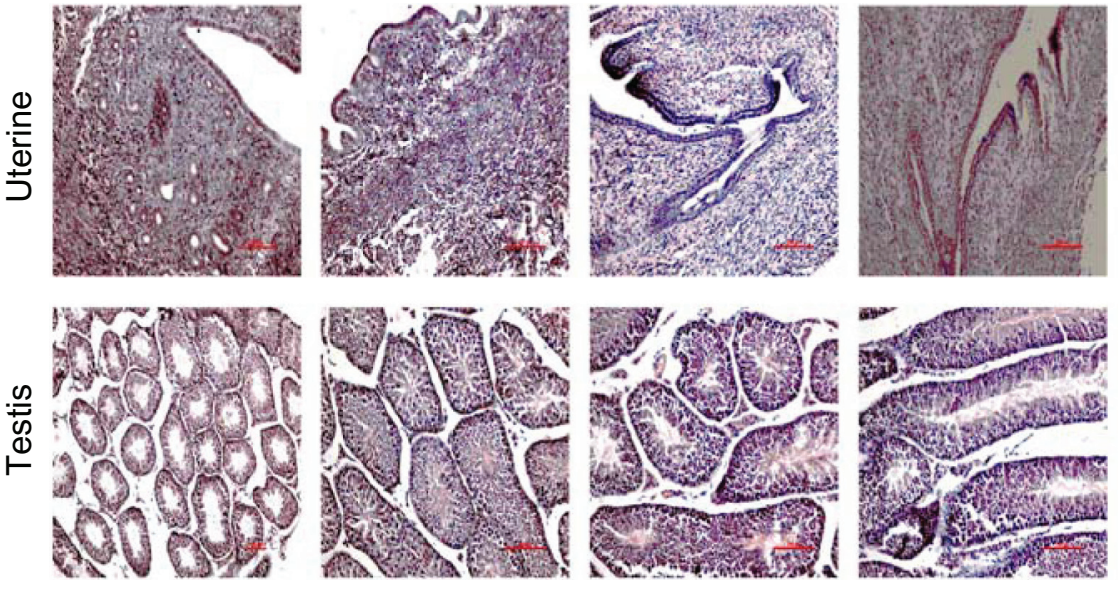

$36.1 \mathrm{~nm}$
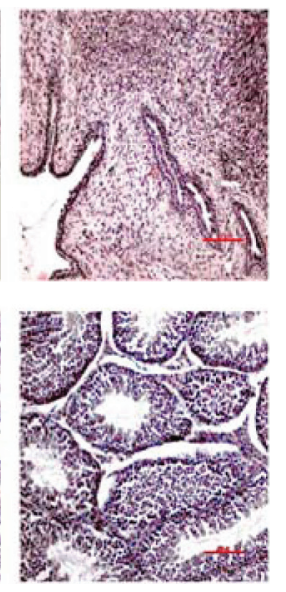

Figure 7 Pathological results from the uterus of female mice and testis of male mice after 28 days. Appreciable pathological changes were not found in the organs.

proteins (such as albumin, fibrinogen, $\gamma$-globulin, histone, and insulin), and the degree of binding between NPs and proteins was increased with increasing size. ${ }^{46,47}$ We speculate that pharmacokinetics of PEG-coated NPs is closely related to the sex of mice. Further, these interactions, such as enhanced binding and conformational change of the proteins, may influence the sex differences in toxicity. Thus, further study is necessary to understand mechanisms of sex differences in toxicity of gold NPs. Meanwhile, it is not clear that these NPs in the liver or kidney will cause abnormal gene expression for male and female mice. Changes in key indicators such as ALT and AST are still not clear after 6 months. Therefore, there is still much room for subsequent work.

\section{Conclusion}

In summary, we carried out a study about sex differences in toxicity of gold NP-treated mice. Gold NP treatment of mice did not induce significant change in body weight. The gold NPs, however, caused significant increases in spleen and thymus indexes, which represented the activation of immune response, for female mice but not male mice. Further hematology results showed 22.5 and $36.1 \mathrm{~nm}$ gold NPs caused obvious increases of WBC and RBC in male mice, indicating infection occurred, but this was not significant in female mice. In further analysis, it was found that male mice also suffered significant liver toxicity, with ALT and AST significantly increased, and except for that, obvious kidney toxicity could be found in female mice. For size effects, $4.4 \mathrm{~nm}$ gold NPs presented low liver toxicity and minimal infection, but 22.5, 29.3, and $36.1 \mathrm{~nm}$ gold NPs showed significant liver and kidney toxicity, among which the toxicity of $22.5 \mathrm{~nm}$ gold NPs was the highest.
Also, these NPs did not cause appreciable toxicity in reproductive systems 28 days after injection. Generally, male mice presented significant liver toxicity, and female mice presented high kidney toxicity. These findings will give us insights to sex differences in nanotoxicology.

\section{Acknowledgments}

This work was supported by the National Natural Science Foundation of China (grant 81000668), the Natural Science Foundation of Tianjin (grant 13JCQNJC13500), the Subject Development Foundation of the Institute of Radiation Medicine, CAMS (grants SF1207 and SZ1336), and the Foundation of Union New Star, CAMS. Prof Sun would like to thank the National Natural Science Foundation of China (grant 30970867) for its support.

\section{Disclosure}

The authors report no conflicts of interest in this work.

\section{References}

1. Elghanian R, Storhoff JJ, Mucic RC, Letsinger RL, Mirkin CA. Selective colorimetric detection of polynucleotides based on the distancedependent optical properties of gold nanoparticles. Science. 1997;277: 1078-1081.

2. Sokolov K, Follen M, Aaron J, et al. Real-time vital optical imaging of precancer using anti-epidermal growth factor receptor antibodies conjugated to gold nanoparticles. Cancer Res. 2003;63:1999-2004.

3. Murphy CJ, Gole AM, Stone JW, et al. Gold nanoparticles in biology: beyond toxicity to cellular imaging. Acc Chem Res. 2008;41: $1721-1730$.

4. Huang X, El-Sayed IH, Qian W, El-Sayed MA. Cancer cell imaging and photothermal therapy in the near-infrared region by using gold nanorods. J Am Chem Soc. 2006;128:2115-2120.

5. Day ES, Bickford LR, Slater JH, Riggall NS, Drezek RA, West JL. Antibody-conjugated gold-gold sulfide nanoparticles as multifunctional agents for imaging and therapy of breast cancer. Int $J$ Nanomedicine. 2010;5:445-454. 
6. Ghosh P, Han G, De M, Kim CK, Rotello VM. Gold nanoparticles in delivery applications. Adv Drug Deliv Rev. 2008;60:1307-1315.

7. Giljohann DA, Seferos DS, Daniel WL, Massich MD, Patel PC, Mirkin CA. Gold nanoparticles for biology and medicine. Angew Chem Int Ed Engl. 2010;49:3280-3294.

8. Eustis S, El-Sayed MA. Why gold nanoparticles are more precious than pretty gold: noble metal surface plasmon resonance and its enhancement of the radiative and nonradiative properties of nanocrystals of different shapes. Chem Soc Rev. 2006;35:209-217.

9. Boisselier E, Astruc D. Gold nanoparticles in nanomedicine: preparations, imaging, diagnostics, therapies and toxicity. Chem Soc Rev. 2009;38:1759-1782.

10. Hu M, Chen J, Li ZY, et al. Gold nanostructures: engineering their plasmonic properties for biomedical applications. Chem Soc Rev. 2006;35:1084-1094.

11. Wang S, Huang P, Nie L, et al. Single continuous wave laser induced photodynamic/plasmonic photothermal therapy using photosensitizer - functionalized gold nanostars. Adv Mater. Epub February 13, 2013.

12. Luo Z, Yuan X, Yu Y, et al. From the aggregation-induced emission of $\mathrm{Au}(\mathrm{I})$-thiolate complexes to ultrabright $\mathrm{Au}(0) @ \mathrm{Au}(\mathrm{I})$-thiolate core-shell nanoclusters. J Am Chem Soc. 2012;134:16662-16670.

13. Xie J, Zheng Y, Ying JY. Protein-directed synthesis of highly fluorescent gold nanoclusters. J Am Chem Soc. 2009;131:888-889.

14. Chithrani DB, Jelveh S, Jalali F, et al. Gold nanoparticles as radiation sensitizers in cancer therapy. Radiat Res. 2010;173:719-728.

15. Hainfeld JF, Slatkin DN, Smilowitz HM. The use of gold nanoparticles to enhance radiotherapy in mice. Phys Med Biol. 2004;49:N309-N315.

16. Zhang XD, Wu D, Shen X, et al. Size-dependent radiosensitization of PEG-coated gold nanoparticles for cancer radiation therapy. Biomaterials. 2012;33:6408-6419.

17. Zhang XD, Guo ML, Wu HY, et al. Irradiation stability and cytotoxicity of gold nanoparticles for radiotherapy. Int J Nanomedicine. 2009;4: $165-173$.

18. Hauck TS, Anderson RE, Fischer HC, Newbigging S, Chan WC. In vivo quantum-dot toxicity assessment. Small. 2009;6:138-144.

19. Connor EE, Mwamuka J, Gole A, Murphy CJ, Wyatt MD. Gold nanoparticles are taken up by human cells but do not cause acute cytotoxicity. Small. 2005;1:325-327.

20. Chen H, Dorrigan A, Saad S, Hare DJ, Cortie MB, Valenzuela SM. In vivo study of spherical gold nanoparticles: inflammatory effects and distribution in mice. PLoS One. 2013;8:e58208.

21. Söderstjerna E, Johansson F, Klefbohm B, Englund Johansson U. Goldand silver nanoparticles affect the growth characteristics of human embryonic neural precursor cells. PLoS One. 2013;8:e58211.

22. Goodman CM, McCusker CD, Yilmaz T, Rotello VM. Toxicity of gold nanoparticles functionalized with cationic and anionic side chains. Bioconjug Chem. 2004;15:897-900.

23. Hauck TS, Ghazani AA, Chan WC. Assessing the effect of surface chemistry on gold nanorod uptake, toxicity, and gene expression in mammalian cells. Small. 2007;4:153-159.

24. Zhang XD, Wu D, Shen X, Liu PX, Fan FY, Fan SJ. In vivo renal clearance, biodistribution, toxicity of gold nanoclusters. Biomaterials. 2012;33:4628-4638.

25. Pan Y, Neuss S, Leifert A, et al. Size-dependent cytotoxicity of gold nanoparticles. Small. 2007;3:1941-1949.

26. Chithrani BD, Ghazani AA, Chan WC. Determining the size and shape dependence of gold nanoparticle uptake into mammalian cells. Nano Lett. 2006;6:662-668.

27. De Jong WH, Hagens WI, Krystek P, Burger MC, Sips AJ, Geertsma RE. Particle size-dependent organ distribution of gold nanoparticles after intravenous administration. Biomaterials. 2008;29:1912-1919.
28. Cho WS, Cho M, Jeong J, et al. Acute toxicity and pharmacokinetics of $13 \mathrm{~nm}$-sized PEG-coated gold nanoparticles. Toxicol Appl Pharmacol. 2009;236:16-24.

29. Zhang XD, Wu D, Shen X, et al. Size-dependent in vivo toxicity of PEGcoated gold nanoparticles. Int J Nanomedicine. 2011;6:2071-2081.

30. Cho WS, Cho M, Jeong J, et al. Size-dependent tissue kinetics of PEG-coated gold nanoparticles. Toxicol Appl Pharmacol. 2010;245: $116-123$.

31. Zhang XD, Wu HY, Wu D, et al. Toxicologic effects of gold nanoparticles in vivo by different administration routes. Int $J$ Nanomedicine. 2010;5:771-781.

32. Niidome T, Yamagata M, Okamoto Y, et al. PEG-modified gold nanorods with a stealth character for in vivo applications. $J$ Control Release. 2006;114:343-347.

33. Zhang G, Yang Z, Lu W, et al. Influence of anchoring ligands and particle size on the colloidal stability and in vivo biodistribution of polyethylene glycol-coated gold nanoparticles in tumor-xenografted mice. Biomaterials. 2009;30:1928-1936.

34. Lipka J, Semmler-Behnke M, Sperling RA, et al. Biodistribution of PEG-modified gold nanoparticles following intratracheal instillation and intravenous injection. Biomaterials. 2010;31:6574-6581.

35. von Maltzahn G, Park J-H, Agrawal A, et al. Computationally guided photothermal tumor therapy using long-circulating gold nanorod antennas. Cancer Res. 2009;69:3892-3900.

36. Xiao K, Li Y, Luo J, et al. The effect of surface charge on in vivo biodistribution of PEG-oligocholic acid based micellar nanoparticles. Biomaterials. 2011;32:3435-3446.

37. Balasubramanian SK, Jittiwat J, Manikandan J, Ong CN, Yu LE, Ong WY. Biodistribution of gold nanoparticles and gene expression changes in the liver and spleen after intravenous administration in rats. Biomaterials. 2010;31:2034-2042.

38. Beierle I, Meibohm B, Derendorf H. Gender differences in pharmacokinetics and pharmacodynamics. Int J Clin Pharmacol Ther. 1999;37:529-547.

39. Gleiter C, Gundert-Remy U. Gender differences in pharmacokinetics. Eur J Drug Metab Pharmacokinet. 1996;21:123-128.

40. Kim WY, Kim J, Park JD, Ryu HY, Yu IJ. Histological study of gender differences in accumulation of silver nanoparticles in kidneys of Fischer 344 rats. J Toxicol Environ Health A. 2009;72:1279-1284.

41. Kim YS, Kim JS, Cho HS, et al. Twenty-eight-day oral toxicity, genotoxicity, and gender-related tissue distribution of silver nanoparticles in Sprague-Dawley rats. Inhal Toxicol. 2008;20:575-583.

42. Turkevich J, Stevenson PC, Hillier J. A study of the nucleation and growth processes in the synthesis of colloidal gold. Discuss Faraday Soc. 1951;11:55-75.

43. Mie G. A contribution to the optics of turbid media, especially colloidal metallic suspensions. 1908;2:377-445.

44. Wu D, Zhang XD, Liu PX, Zhang LA, Fan FY, Guo ML. Gold nanostructure: fabrication, surface modification, targeting imaging, and enhanced radiotherapy. Curr Nanosci. 2011;7:110-118.

45. Chen Z, Meng H, Xing G, et al. Acute toxicological effects of copper nanoparticles in vivo. Toxicol Lett. 2006;163:109-120.

46. Lacerda SHDP, Park JJ, Meuse C, et al. Interaction of gold nanoparticles with common human blood proteins. ACS Nano. 2009;4:365-379.

47. Dobrovolskaia MA, Patri AK, Zheng J, et al. Interaction of colloidal gold nanoparticles with human blood: effects on particle size and analysis of plasma protein binding profiles. Nanomedicine. 2009;5: 106-117. 
International Journal of Nanomedicine

Dovepress

\section{Publish your work in this journal}

The International Journal of Nanomedicine is an international, peerreviewed journal focusing on the application of nanotechnology in diagnostics, therapeutics, and drug delivery systems throughou the biomedical field. This journal is indexed on PubMed Central, MedLine, CAS, SciSearch ${ }^{\circledR}$, Current Contents ${ }^{\circledR} /$ Clinical Medicine,
Journal Citation Reports/Science Edition, EMBase, Scopus and the Elsevier Bibliographic databases. The manuscript management system is completely online and includes a very quick and fair peer-review system, which is all easy to use. Visit http://www.dovepress.com/ testimonials.php to read real quotes from published authors.

Submit your manuscript here: http://www.dovepress.com/international-journal-of-nanomedicine-journal 